\title{
Arahan Peningkatan Pelayanan Kereta Komuter Surabaya-Lamongan Berdasarkan Preferensi Masyarakat
}

\author{
Wiratama Adi Nugraha dan Sarjito \\ Departemen Perencanaan Wilayah dan Kota, Fakultas Teknik Sipil dan Perencanaan, Institut \\ Teknologi Sepuluh Nopember (ITS) \\ e-mail: sardjito24@yahoo.com
}

\begin{abstract}
Abstrak-Sebagai kota besar, Surabaya menjadi penarik pergerakan dari wilayah sekitarnya ke Kota Surabaya. Salah satu pelaku pergerekan adalah pekerja komuter yang berada di Kabupaten Lamongan untuk berkerja di Kota Surabaya. Salah satu moda transportasi yang digunakan untuk pergerakan tersebut adalah dengan menggunakan kereta komuter SurabayaLamongan. Dalam penyelenggara kereta komuter sampai saat ini masih belum diminati oleh calon pengguna, hal ini bisa dilihat dari masih rendahnya okupansi kereta (dibawah 50\%) serta tren penurun jumlah penumpang kereta komuter dari tahun ke tahun. Oleh karena itu perlu ada upaya peningkatan okupansi penumpang kereta komuter Surabaya-Lamongan melihat dari preferensi masyarakat. Tujuan dari penelitian ini adalah untuk merumuskan arahan peningkatan pelayanan kereta komuter Surabaya-Lamongan berdasarkan preferensi masyarakat. Pada awalnya variabel pelayanan ditentukan terlebih dahulu melalui studi litratur yang disesuaikan dengan kondisi lapangan melalui analisis delphi. Pengukuran kepuasan pelayanan dilihat dengan analisis service quality yang melihat tingkat kepuasan dan tingkat harapan pada suatu pelayanan beserta pebobotan masing-masing variabel pelayanan dengan menggunakan pembobotan AHP. Setelah itu dilakukan analisis triangulasi untuk menentukan arahan peningkatan pelayanannya dengan menggabungkan hasl kepuasan pelayanan yang menjadi prioritas, kondisi lapangan, regulasi, serta studi kasus yang ada. Hasil analisis ini berupa arahan layanan di pelayanan internal dan eksternal kereta komuter Surabaya-Lamongan. Pelayanan internal meliputi beberapa arahan berupa perbaikan pola operasional dan lalu lintas kereta api agar perjalanan lebih cepat dan tepat waktu, menambah fitur keamanan, potensi penambahan frekuensi pelayanan, perlunya studi penambahan stasiun, serta perbaikan kenyamanan sesuai standar. Pada pelayanan eksternal, arahan meliputi memperbanyak frekuensi angkutan umum, memperbanyak halte angkutan umum, mempersingkat headway, serta peningkatan keamanan angkutan umum.
\end{abstract}

Kata Kunci-Pelayanan Kereta Komuter, Preferensi Masyarakat.

\section{PENDAHULUAN}

$\mathrm{D}$ ALAM pengembangan dan perencanaan suatu wilayah, sektor transportasi adalah salah satu sektor yang sangat penting dan strategis dalam perkembangan suatu wilayah. Hal ini tak lepas dalam fungsi transportasi dalam menggerakkan atau memindahkan orang atau/dan barang dari satu tempat ke tempat lain dengan sistem tertentu untuk tujuan tertentu. Dalam melihat supply dan demand, permintaan jasa transportasi akan terjadi ketika ada faktor-faktor yang mendorongnya, baik dari segi internal maupun segi eksternal. Pergerakan transportasi yang baik akan meningkatkan siklus perekonomian, sehingga pertumbuhan ekonomi suatu daerah atau antar daerah dapat lebih cepat, maka dari itu keberadaan transportasi juga menjadi faktor penting yang memengaruhi pertumbuhan ekonomi suatu wilayah [1].

Kota Surabaya-Kabupaten Lamongan telah memiliki kereta api komuter sejak tanggal 9 Februari 2006. Kereta komuter merupakan inovasi PT Kereta Api Indonesia DAOP VIII Surabaya dalam memberikan alternatif moda transportasi bagi masyarakat yang melakukan perjalanan komuter dari daerah sekitar Kota Surabaya ke Kota Surabaya.

Berdasarkan Grafik Perjalanan Kereta Api (GAPEKA) tahun 2015, saat ini hanya ada dua kali pejalanan pulang pergi kereta api komuter dari Surabaya ke Lamongan, yaitu pada pagi dan malam. Rute kereta komuter yang ditempuh melalui Stasiun Lamongan dengan tujuan akhir Stasiun Surabaya Pasar Turi. Perjalanan kereta komuter dari Surabaya ke Lamongan ditempuh selama 1 jam 4 menit.[2]

Frekuensi perjalanan kereta komuter yang hanya dua kali perjalanan pulang pergi (pagi dan malam). Kapasitas satu gerbong kereta komuter Surabaya Lamongan sebesar 178 penumpang dan dengan kondisi saat ini dimana jumlah gerbong sebanyak 4 gerbong maka satu rangkaian kereta komuter yang terdiri dari 4 gerbong memiliki kapasitas penumpang maksimal 712 penumpang.[3]

Data kondisi fakta pelayanan kereta api dalam Rencana Induk Perkeretaapian Jawa Timur 2016-2036 memperlihatkan jumlah volume penumpang kereta komuter SurabayaLamongan pada pagi hari sebesar 63 penumpang (okupansi $8,84 \%$ ) penumpang dari Surabaya ke Lamongan dan 270 penumpang (okupansi 37,92\%) penumpang dari Lamongan ke Surabaya, sedangkan pada malam hari volume penumpang kereta komuter sebesar 249 penumpang (okupansi 34,97\%) dari Surabaya ke Lamongan dan pada perjalanan baliknya sebesar 106 penumpang (okupansi 14,88\%). Data dari kurang dari Rencana Induk Perkeretaapian Jawa Timur 2013 menunjukkan jumlah penumpang kereta komuter dalam setiap perjalanannya memiliki okupansi kurang dari 50\% dari kapasitas maksimalnya. Sebelumnya, Pambudi (2010) juga melakukan penelitian yang memperlihatkan jumlah maksimum penumpang kereta komuter Surabaya-Lamongan tidak pernah lebih dari 240 penumpang (okupansi 33,7\%). Okupansi yang 
masih dibawah $50 \%$ dalam setiap perjalanannya mengindikasikan masih belum maksimalnya pelayanan kereta komuter dalam menarik potensi penumpang dari Lamongan ke Surabaya dan sebaliknya.[3] [4]

Data dari PT. Kereta Api Indonesia tahun 2013 sampai November 2016 menunjukkan terjadinya tren penurunan jumlah penumpang Kereta Komuter Surabaya-Lamongan. Pada tahun 2013 total jumlah penumpang sebesar 306.130 penumpang, pada tahun 2014 sebesar 280.117, pada tahun 2015 sebesar 260.427, dan pada data 2016 sampai bulan November sebesar 202.992. Hal ini menunjukkan jumlah penumpang Kereta Komuter Surabaya-Lamongan yang semakin lama semakin menurun.

Pengembangan transportasi tak lepas dari preferensi masyarakat dalam menunjukkan transportasi yang ideal bagi individu masyarakat, dikarenakan preferensi transportasi umum dipengaruhi oleh fenomena captive and choice. Kelompok masyarakat yang mempertimbangkan aksesbilitas serta mobilitas dan memiliki akses kendaraan pribadi disebut choice, sedangkan captive adalah kelompok masyarakat yang senantiasa menggunakan transportasi umum. Salah satu hal yang mempengaruhi preferensi penumpang adalah faktor pelayanan. Faktor pelayanan seperti aksesbilitas, ketepatan waktu perjalanan, kebersihan, kenyamanan, martabat penumpang, biaya perjalanan, pencemaran udara, kemacetan jalan, juga menjadi faktor-faktor menentukan seseorang menggunakan angkutan umum.[1] [5]

Untuk merencanakan moda transportasi yang mengedepankan efektifitas dari peningkatan pelayanan transportasi maka diperlukan informasi preferensi dari calon pengguna moda angkutan tersebut. Dikarenakan masih rendahnya penggunaan kereta komuter Surabaya-Lamongan, maka perlu digali mengenai penyebab rendahnya kualitas pelayanan kereta komuter Surabaya-Lamongan, sehingga perlu digali preferensi dari masyarakat untuk mengetahui apa saja yang diperlukan untuk meningkatkan perlayanan kereta komuter Surabaya-Lamongan. Preferensi pengguna kereta komuter dalam fokus peningkatan pelayanan kereta komuter dapat mempengaruhi minat calon penggunaa dalam memanfaatkan kereta komuter Surabaya-Lamongan. [2]

\section{METODE PENELITIAN}

\section{A. Metode Pengumpulan Data}

Dalam melakukan pengumpulan data, dilakukan melalui survey primer dan survei sekunder. Untuk mendapatkan data kepuasan pelayanan dilakukan melalui survei primer menggunakan teknik pengumpulan data berupa pembagian kuesioner ke masyarakat, observasi, dan wawancara ke stakeholder terkait. Sedangkan survei sekunder dilakukan untuk menunjang datadata hasil survei primer dengan menggunakan teknik pengumpulan data melalui survei instansional ke beberapa badan terkait.

\section{B. Metode Analisis}

Dalam tahapan analisis ini, teknik yang digunakan bersifat analisis kualitatif yaitu untuk mendeskripsikan hasil kuesioner yang akan disajikan dalam bentuk tabel, bagan, maupun diagram. Teknik analisis yang digunakan adalah sebagai berikut.

1. Mengeksporasi variabel pelayanan internal dan eksternal manakah yang paling berpengaruh dan sesuai dengan kondisi lapangan dengan analisis delphi.

Analisis Delphi adalah metode yang banyak digunakan dan diterima untuk mengumpulkan data dari responden dalam domain penelitian mereka. Teknik analisis ini dirancang sebagai proses komunikasi kelompok yang bertujuan untuk mencapai konvergensi pendapat tentang isu isu nyata. Proses analisis delphi telah digunakan di berbagai bidang studi seperti perencanaan program, penilaian assesment, penetuan kebijakan, dan pemanfaatan sumber daya untuk mengembangkan berbagai alternatif, menjelajahi atau mengekspos yang mendasari asumsi, serta berkorelasi penilaian pada suatu topik yang mencakup berbagai disiplin ilmu.

2. Menggali tingkat kepuasan dan kepentingan pelayanan internal dan eksternal kereta komuter Surabaya-Lamongan berdasarkan faktor dan variabel pelayanan kereta komuter dengan menggunakan analisis tingkat kepuasan.

Untuk mengolah data pengguna kereta komuter dilakukan gap analysis untuk mengetahui selisih antara tingkat kepuasannya. Tingkat kepuasan merupakan gap antara kenyataan yang dialami pengguna dengan harapan yang diinginkan oleh pengguna. Sehingga untuk menghitung tingkat kepuasan dilakukan pengurangan rata-rata tingkat kenyataan dengan tingkat harapan.

Dalam analisis tingkat kepuasan ini terdapat dua buah variabel yang diwakili oleh huruf $\mathrm{X}$ dan $\mathrm{Y}$, dimana $\mathrm{X}$ merepresentasikan tingkat kenyataan yang dirasakan pengguna, sedangkan Y merupakan tingkat harapan pengguna. Adapun rumus yang digunakan adalah sebagai berikut:

Dimana $\quad X=\frac{2 X i}{n} \quad Y=\frac{2 Y i}{n}$

$\mathrm{X}=$ Skor rata-rata tingkat pelaksanaan/kepuasan

$\mathrm{Y}=$ Skor rata-rata tingkat kepentingan

$\mathrm{n}=$ Jumlah responden

Setelah didapat nilai $\mathrm{X}$ dan $\mathrm{Y}$, maka selanjutnya adalah mencari selisih X dan Y. Nilai selisih yang bernilai lebih dari sama dengan 0 mengindikasikan pengguna telah puas dengan variabel yang dinyatakan, sedangkan nilai negatif menyatakan pengguna tidak puas. Analisis tingkat kepuasan akan digunakan untuk mengetahui tingkat kepuasan pelayanan kereta komuter serta mengetahui tingkat kepentingan pelayanan tersebut dalam kereta komuter. Dengan menanyakan kepentingan dan kepuasan pelayanan kereta komuter, akan didapat tingkat kepuasan pelayanan dan kepentingan pelayanan.

3. Pembobotan kriteria, faktor, dan variabel pelayanan internal dan eksternal dari masing-masing stakeholder dengan menggunakan analisis Analytic Hierarchy Process (AHP)

Analytical Hierarchy Process (AHP) adalah metode analisis pengambilan keputusan berhirarki yang dibangun oleh Prof. Thomas L. Saaty di University of Pittsburg pada tahun 1970. 
AHP pertama kali diaplikasikan dalam perencanaan militer Amerika Serikat dalam menghadapi berbagai kemungkinan (contigency planning). Proses ini bergantung pada imajinasi, pengalaman, dan pengetahuan untuk menyusun hirarki suatu masalah pada logika, intuisi, dan pengalaman untuk memberikan pertimbangan. Proses ini juga memungkinkan pengujian kepekaan hasilnya terhadap perubahan informasi. Secara kualitatif, metode ini mendefinisikan masalah dan penilaian. Sedangkan secara kuantitatif, AHP melakukan perbandingan dan penilaian untuk mendapatkan solusi.[6]

4. Menentukan prioritas dari peningkatan pelayanan internal dan eksternal kereta komuter Surabaya-Lamongan berdasarkan preferensi masyarakat dengan menggunakan analisis Service Quality (ServQual)

Analisis ServQual adalah suatu kuesioner yang digunakan untuk mengukur kualitas jasa. Cara ini mulai dikembangkan pada tahun 1985 oleh Zeithaml, Parasuraman, dan Berry dan telah digunakan dalam mengukur berbagai kualitas jasa. Dengan kuesioner ini, kita bisa mengetahui seberapa besar celah (gap) yang ada di antara persepsi pelanggan dan ekspektasi pelanggan terhadap suatu perusahaan jasa. Kuesioner servqual dapat diubah-ubah (disesuaikan) agar cocok dengan industri jasa yang berbeda-beda pula (misalnya bank, restoran, atau perusahaan telekomunikasi). [7]

5. Merumuskan arahan peningkatan pelayanan kereta komuter Surabaya-Lamongan dari segi pelayanan internal dan eksternal berdasarkan preferensi pengguna dengan menggunakan analisis triangulasi.

Triangulasi pada dasarnya merupakan pengujian dari hal-hal yang didapatkan peneliti untuk dibuat sebuah hasil. Dalam hal ini, proses triangulasi menggabungkan data dari hal yang berkaitan dengan penelitian, kemudian disatukan untuk menunjang tujuan penelitian sehingga dihasilkan suatu hal yang sesuai dengan apa yang diinginkan oleh penelitian. Analisis triangulasi digunakan dengan menggunakan sumbersumber yang berkaitan dengan penelitian tersebut, sehingga akan menghasilkan tujuan yang ingin diraih oleh peneliti.[8]

\section{HASIL DAN PEMBAHASAN}

A. Mengeksporasi variabel pelayanan internal dan eksternal manakah yang paling berpengaruh dan sesuai dengan kondisi lapangan dengan analisis delphi.

Dalam prosesnya, terjadi dua kali iterasi, dimana iterasi pertama ada 7 variabel yang tidak setuju, dan pada iterasi kedua semua stakeholder setuju dengan semua variabel yang ada.

Tabel 1.

Hasil Analisis Delphi

\begin{tabular}{|c|c|c|c|c|}
\hline Kriteria & Faktor & Variabel & $\begin{array}{c}\text { Iterasi } \\
\text { I }\end{array}$ & $\begin{array}{c}\text { Iterasi } \\
\text { II }\end{array}$ \\
\hline Pelayanan & Aksesbilitas & Jarak menuju halte. & TS & $\mathrm{S}$ \\
\hline \multirow[t]{3}{*}{ Eksternal } & Waktu & Waktu perjalanan & S & $\mathrm{S}$ \\
\hline & & $\begin{array}{l}\text { Waktu menunggu } \\
\text { angkutan umum ke } \\
\text { stasiun }\end{array}$ & $\mathrm{S}$ & $\mathrm{S}$ \\
\hline & Biaya & Tarif angkutan umum & $\mathrm{S}$ & $\mathrm{S}$ \\
\hline
\end{tabular}

\begin{tabular}{|c|c|c|c|c|}
\hline & & $\begin{array}{l}\text { Biaya keseluruhan } \\
\text { untuk perjalanan dari } \\
\text { tempat awal } \\
\text { perjalanan ke stasiun. }\end{array}$ & $\bar{S}$ & $\overline{\mathrm{S}}$ \\
\hline & Pelayanan & Kenyamanan & $\mathrm{S}$ & $\mathrm{S}$ \\
\hline & & Keamanan & $\mathrm{S}$ & $\mathrm{S}$ \\
\hline & & $\begin{array}{l}\text { Ketersediaan } \\
\text { informasi }\end{array}$ & $\mathrm{S}$ & $\mathrm{S}$ \\
\hline & & $\begin{array}{l}\text { Ketersediaan fasilitas } \\
\text { penunjang }\end{array}$ & $\mathrm{S}$ & $\mathrm{S}$ \\
\hline & & $\begin{array}{l}\text { Ketersediaan park } \\
\text { and ride di stasiun }\end{array}$ & $\mathrm{S}$ & $\mathrm{S}$ \\
\hline & & Inovasi pelayanan. & TS & S \\
\hline & Kehandalan & Headway. & & $\mathrm{S}$ \\
\hline & & $\begin{array}{l}\text { Kecepatan tempuh } \\
\text { angkutan umum }\end{array}$ & TS & $\mathrm{S}$ \\
\hline & & $\begin{array}{l}\text { Frekuensi pelayanan } \\
\text { angkutan umum }\end{array}$ & $\mathrm{S}$ & $\mathrm{S}$ \\
\hline Pelayanan & Aksesbilitas & Pesebaran stasiun & TS & $\mathrm{S}$ \\
\hline Internal & Waktu & $\begin{array}{l}\text { Lama Perjalanan } \\
\text { Kereta Komuter }\end{array}$ & TS & $\mathrm{S}$ \\
\hline & Biaya & Tarif & $\mathrm{S}$ & $\mathrm{S}$ \\
\hline & & $\begin{array}{l}\text { Biaya keseluruhan } \\
\text { dalam melakukan } \\
\text { perjalanan dengan } \\
\text { kereta komuter }\end{array}$ & $\mathrm{S}$ & $\mathrm{S}$ \\
\hline & Pelayanan & Kenyamanan & $\mathrm{S}$ & $\mathrm{S}$ \\
\hline & & $\begin{array}{l}\text { Ketersediaan fasilitas } \\
\text { penunjang }\end{array}$ & $\mathrm{S}$ & $\mathrm{S}$ \\
\hline & & Keamanan & $\mathrm{S}$ & $\mathrm{S}$ \\
\hline & & $\begin{array}{l}\text { Ketersediaan } \\
\text { informasi }\end{array}$ & $\mathrm{S}$ & $\mathrm{S}$ \\
\hline & & Inovasi pelayanan & TS & $\mathrm{S}$ \\
\hline & Kehandalan & Ketepatan waktu & $\mathrm{S}$ & $\mathrm{S}$ \\
\hline & & Kecepatan tempuh & TS & $\mathrm{S}$ \\
\hline & & Frekuensi pelayanan & $\mathrm{S}$ & $\mathrm{S}$ \\
\hline
\end{tabular}

Sumber: Hasil Analisis, 2017

B. Menggali tingkat kepuasan dan kepentingan pelayanan internal dan eksternal kereta komuter Surabaya-Lamongan berdasarkan faktor dan variabel pelayanan kereta komuter dengan menggunakan analisis tingkat kepuasan.

Dari hasil pembobotan terhadap masing-masing jawaban dari 188 responden pengguna kereta komuter dan masyarakat yang wilayahnya dilintasi kereta komuter (baik yang pernah naik kereta komuter atau yang mengetahui kondisi kereta komuter), dapat diketahui tingkat kepuasan mereka terhadap tiap variabel.

Tabel 2.

Hasil Analisis Kepuasan Pelayanan Kereta Komuter

\begin{tabular}{lllc}
\hline \hline \multicolumn{1}{c}{ Kriteria } & Faktor & \multicolumn{1}{c}{ Variabel } & Keterangan \\
\hline Pelayanan & Aksesbilitas & Jarak menuju & Tidak Memuaskan \\
Eksternal & & halte. & Tidak Memuaskan \\
& Waktu & $\begin{array}{l}\text { Waktu } \\
\text { perjalanan }\end{array}$ & \\
& & $\begin{array}{l}\text { Waktu } \\
\text { menunggu }\end{array}$ & Tidak Memuaskan \\
& & angkutan & \\
& & umum ke & \\
& & stasiun & \\
& & Tarif angkutan \\
& umum & Tidak Memuaskan \\
& Biaya & & \\
\hline \hline
\end{tabular}




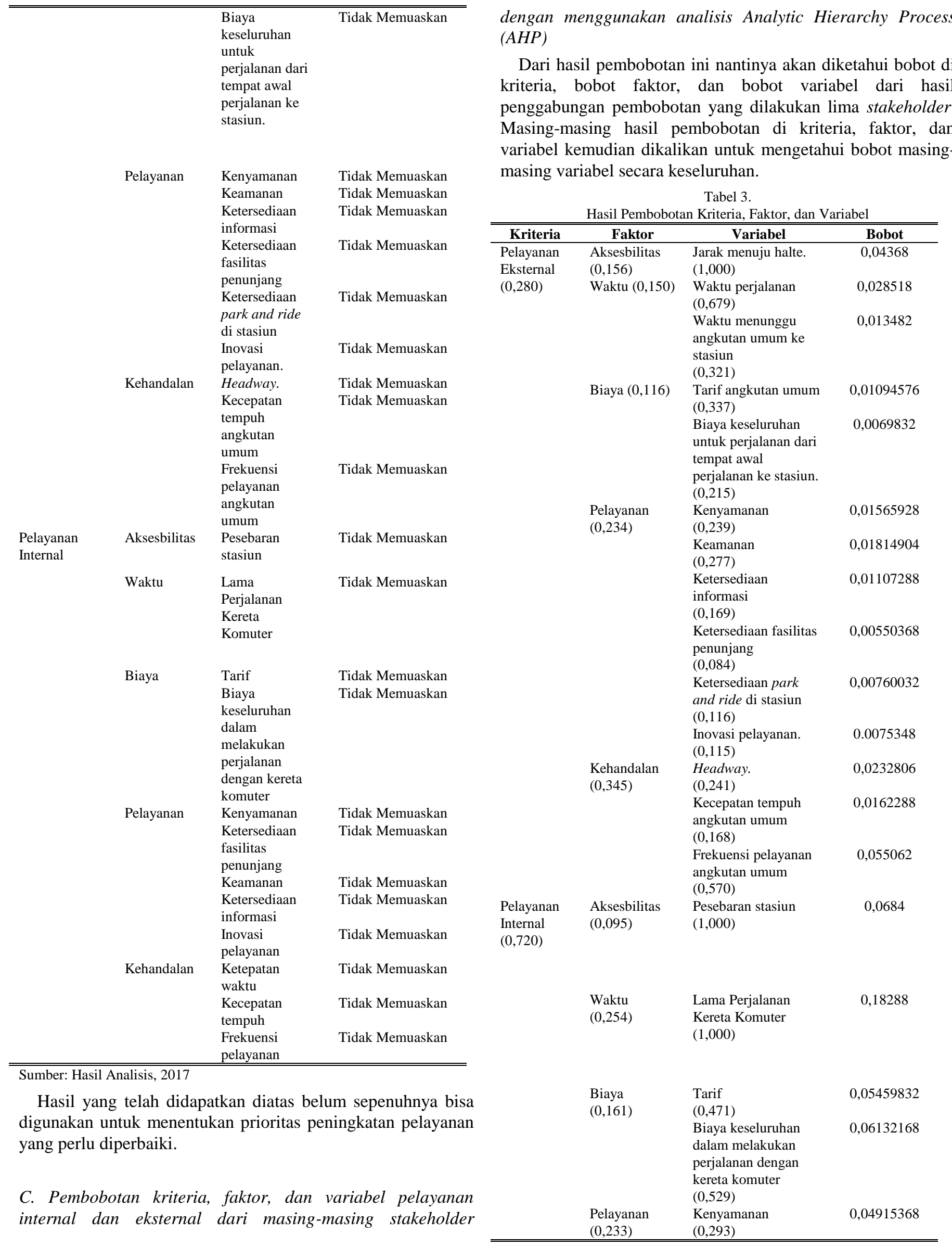




\begin{tabular}{llc}
\hline \hline & $\begin{array}{l}\text { Ketersediaan fasilitas } \\
\text { penunjang } \\
(0,066)\end{array}$ & 0,01107216 \\
& $\begin{array}{l}\text { Keamanan } \\
(0,402)\end{array}$ & 0,06743952 \\
& $\begin{array}{l}\text { Ketersediaan } \\
\text { informasi } \\
(0,100)\end{array}$ & 0,0163566 \\
& $\begin{array}{l}\text { Inovasi pelayanan } \\
(0,139)\end{array}$ & 0,02331864 \\
Kehandalan & $\begin{array}{l}\text { Ketepatan waktu } \\
(0,640)\end{array}$ & 0,1184256 \\
& $\begin{array}{l}\text { Kecepatan tempuh } \\
(0,071)\end{array}$ & 0,01313784 \\
& $\begin{array}{l}\text { Frekuensi pelayanan } \\
(0,289)\end{array}$ & 0,05347656 \\
\hline \hline
\end{tabular}

Sumber: Hasil Analisis, 2017

D. Menentukan prioritas dari peningkatan pelayanan internal dan eksternalkereta komuter Surabaya-Lamongan berdasarkan preferensi masyarakat dengan menggunakan analisis Service Quality (ServQual)

Pada analisis ServQual, analisis ini dilakukan dengan mengalikan selisih nilai X-Y tiap variabel dengan bobot nilai variabel yang telah dilakukan melalui analisis AHP. Kemudian diambil 10 variabel dengan nilai ServQual terkecil untuk diberi prioritas peningkatan pelayanan. Berikut ini adalah hasil analisis ServQual.

Tabel 4.

Hasil ServQual (Diurut dari Nilai Terendah ke Tertinggi)

\begin{tabular}{|c|c|c|c|}
\hline Kriteria & Faktor & Variabel & Nilai ServQual \\
\hline $\begin{array}{l}\text { Pelayanan } \\
\text { Internal }\end{array}$ & Waktu & $\begin{array}{l}\text { Lama Perjalanan Kereta } \\
\text { Komuter }\end{array}$ & -0.0950976 \\
\hline $\begin{array}{l}\text { Pelayanan } \\
\text { Internal }\end{array}$ & Pelayanan & Ketepatan waktu & -0.081713664 \\
\hline $\begin{array}{l}\text { Pelayanan } \\
\text { Internal }\end{array}$ & Pelayanan & Frekuensi pelayanan & -0.078770973 \\
\hline $\begin{array}{l}\text { Pelayanan } \\
\text { Eksternal }\end{array}$ & Pelayanan & $\begin{array}{l}\text { Frekuensi pelayanan } \\
\text { angkutan umum }\end{array}$ & -0.06662502 \\
\hline $\begin{array}{l}\text { Pelayanan } \\
\text { Internal }\end{array}$ & Pelayanan & Keamanan & -0.04923085 \\
\hline $\begin{array}{l}\text { Pelayanan } \\
\text { Internal }\end{array}$ & Aksesbilitas & Pesebaran stasiun & -0.045828 \\
\hline $\begin{array}{l}\text { Pelayanan } \\
\text { Eksternal }\end{array}$ & Aksesbilitas & Jarak menuju halte. & -0.0336336 \\
\hline $\begin{array}{l}\text { Pelayanan } \\
\text { Internal }\end{array}$ & Pelayanan & Kenyamanan & -0.027034524 \\
\hline $\begin{array}{l}\text { Pelayanan } \\
\text { Eksternal }\end{array}$ & Kehandalan & Headway. & -0.025841466 \\
\hline $\begin{array}{l}\text { Pelayanan } \\
\text { Eksternal }\end{array}$ & Pelayanan & Keamanan & -0.023775242 \\
\hline $\begin{array}{l}\text { Pelayanan } \\
\text { Internal }\end{array}$ & Biaya & Tarif & -0.023477278 \\
\hline $\begin{array}{l}\text { Pelayanan } \\
\text { Eksternal }\end{array}$ & Waktu & Waktu perjalanan & -0.02252922 \\
\hline $\begin{array}{l}\text { Pelayanan } \\
\text { Internal }\end{array}$ & Pelayanan & Inovasi pelayanan & -0.019820844 \\
\hline $\begin{array}{l}\text { Pelayanan } \\
\text { Eksternal }\end{array}$ & Pelayanan & Kenyamanan & -0.018321358 \\
\hline $\begin{array}{l}\text { Pelayanan } \\
\text { Eksternal }\end{array}$ & Pelayanan & $\begin{array}{l}\text { Kecepatan tempuh } \\
\text { angkutan umum }\end{array}$ & -0.018176256 \\
\hline $\begin{array}{l}\text { Pelayanan } \\
\text { Eksternal }\end{array}$ & Pelayanan & Ketersediaan informasi & -0.01572349 \\
\hline $\begin{array}{l}\text { Pelayanan } \\
\text { Eksternal }\end{array}$ & Waktu & $\begin{array}{l}\text { Waktu menunggu } \\
\text { angkutan umum ke } \\
\text { stasiun }\end{array}$ & -0.0141561 \\
\hline
\end{tabular}

\begin{tabular}{|c|c|c|c|}
\hline $\begin{array}{l}\text { Pelayanan } \\
\text { Internal }\end{array}$ & Biaya & $\begin{array}{l}\text { Biaya keseluruhan dalam } \\
\text { melakukan perjalanan } \\
\text { dengan kereta komuter }\end{array}$ & -0.012264336 \\
\hline $\begin{array}{l}\text { Pelayanan } \\
\text { Internal }\end{array}$ & Pelayanan & Ketersediaan informasi & -0.011613186 \\
\hline $\begin{array}{l}\text { Pelayanan } \\
\text { Internal }\end{array}$ & Pelayanan & Kecepatan tempuh & -0.009432969 \\
\hline $\begin{array}{l}\text { Pelayanan } \\
\text { Internal }\end{array}$ & Pelayanan & $\begin{array}{l}\text { Ketersediaan fasilitas } \\
\text { penunjang }\end{array}$ & -0.009300614 \\
\hline $\begin{array}{l}\text { Pelayanan } \\
\text { Eksternal }\end{array}$ & Pelayanan & Inovasi pelayanan. & -0.008589672 \\
\hline $\begin{array}{l}\text { Pelayanan } \\
\text { Eksternal }\end{array}$ & Pelayanan & $\begin{array}{l}\text { Ketersediaan park and } \\
\text { ride di stasiun }\end{array}$ & -0.007220304 \\
\hline $\begin{array}{l}\text { Pelayanan } \\
\text { Eksternal }\end{array}$ & Pelayanan & $\begin{array}{l}\text { Ketersediaan fasilitas } \\
\text { penunjang }\end{array}$ & -0.006384269 \\
\hline $\begin{array}{l}\text { Pelayanan } \\
\text { Eksternal }\end{array}$ & Biaya & Tarif angkutan umum & -0.003064813 \\
\hline $\begin{array}{l}\text { Pelayanan } \\
\text { Eksternal }\end{array}$ & Biaya & $\begin{array}{l}\text { Biaya keseluruhan untuk } \\
\text { perjalanan dari tempat } \\
\text { awal perjalanan ke } \\
\text { stasiun. }\end{array}$ & -0.001885464 \\
\hline
\end{tabular}

Sumber: Hasil Analisis, 2017

E. Merumuskan arahan peningkatan pelayanan kereta komuter Surabaya-Lamongan dari segi pelayanan internal dan eksternal berdasarkan preferensi pengguna dengan menggunakan analisis triangulasi.

Analisis Triangulasi digunakan untuk menentukan arahan terhadap variabel-variabel prioritas dengan membandingkan setiap variabel dengan kebijakan terkait. Kesepuluh variabel dengan nilai ServQual terendah telah ditentukan untuk dijadikan prioritas dalam arahan peningkatan pelayanan dikarenakan kondisi variabel pelayanan itu merupakan masalah publik.

Tabel 5.

Arahan Peningkatan Pelayanan Kereta Komuter Suraaya-Lamongan

\begin{tabular}{|c|c|c|}
\hline Kriteria & Variabel & Arahan Peningkatan Pelayanan \\
\hline Pelayanan & Lama & Memperbaiki pola operasional kereta \\
\hline Internal & $\begin{array}{l}\text { Perjalanan } \\
\text { Kereta } \\
\text { Komuter }\end{array}$ & $\begin{array}{l}\text { komuter serta pola lalu lintas kereta api } \\
\text { untuk agar lama perjalanan kompetifi } \\
\text { dengan moda transportasi lainnya. }\end{array}$ \\
\hline $\begin{array}{l}\text { Pelayanan } \\
\text { Internal }\end{array}$ & $\begin{array}{l}\text { Ketepatan } \\
\text { waktu }\end{array}$ & $\begin{array}{l}\text { Memperbaiki pola operasional kereta } \\
\text { komuter serta pola lalu lintas kereta api } \\
\text { agar bisa memperbaiki ketepatan waktu }\end{array}$ \\
\hline $\begin{array}{l}\text { Pelayanan } \\
\text { Internal }\end{array}$ & Keamanan & $\begin{array}{l}\text { Menambah fitur pengamanan serta } \\
\text { menyebarkan petugas keamanan di setiap } \\
\text { gerbong. }\end{array}$ \\
\hline $\begin{array}{l}\text { Pelayanan } \\
\text { Internal }\end{array}$ & $\begin{array}{l}\text { Frekuensi } \\
\text { pelayanan }\end{array}$ & $\begin{array}{l}\text { Memperbaiki jam keberangkatan kereta } \\
\text { serta menambah frekuensi perjalanan di } \\
\text { pagi, siang, dan sore hari agar bisa } \\
\text { mengakomodir kebutuhan masyarakat }\end{array}$ \\
\hline $\begin{array}{l}\text { Pelayanan } \\
\text { Eksternal }\end{array}$ & $\begin{array}{l}\text { Frekuensi } \\
\text { pelayanan } \\
\text { angkutan } \\
\text { umum }\end{array}$ & $\begin{array}{l}\text { Memperbanyak ketersediaan angkutan } \\
\text { umum di waktu yang bersamaan dengan } \\
\text { kedatangan kereta komuter }\end{array}$ \\
\hline $\begin{array}{l}\text { Pelayanan } \\
\text { Internal }\end{array}$ & $\begin{array}{l}\text { Pesebaran } \\
\text { stasiun }\end{array}$ & $\begin{array}{l}\text { Melakukan studi lebih lanjut akan } \\
\text { potensi penambahan pesebaran stasiun di } \\
\text { lokasi yang memungkinkan ditambah } \\
\text { stasiun }\end{array}$ \\
\hline $\begin{array}{l}\text { Pelayanan } \\
\text { Eksternal }\end{array}$ & $\begin{array}{l}\text { Jarak menuju } \\
\text { halte }\end{array}$ & $\begin{array}{l}\text { Menambah halte di depan stasiun serta } \\
\text { memperbaiki akses menuju halte }\end{array}$ \\
\hline $\begin{array}{l}\text { Pelayanan } \\
\text { Internal }\end{array}$ & Kenyamanan & $\begin{array}{l}\text { Memperbaiki kenyamanan di dalam } \\
\text { kereta komuter sesuai dengan peraturan } \\
\text { yang ada, baik di dalam kereta dan di } \\
\text { stasiun }\end{array}$ \\
\hline $\begin{array}{l}\text { Pelayanan } \\
\text { Eksternal }\end{array}$ & Headway & $\begin{array}{l}\text { Menerapkan SOP yang memastikan } \\
\text { hedway yang tidak lama sehingga } \\
\text { masyarakat bisa mudah menjangkau }\end{array}$ \\
\hline
\end{tabular}




\begin{tabular}{ll}
\hline \hline & angkutan umum \\
$\begin{array}{l}\text { Pelayanan Keamerankan SOP pelayanan angkutan } \\
\text { Eksternal }\end{array}$ & $\begin{array}{l}\text { Meneran } \\
\text { umum serta penambahan fitur keamanan }\end{array}$ \\
\hline \hline
\end{tabular}

Sumber:Hasil Analisis, 2017

\section{KESIMPULAN}

Dari hasil analisis yang telah dilakukan maka bisa diambil kesimpulan berkaitan tentang peningkatan pelayanan kereta komuter Surabaya-Lamongan:

1. Kriteria pelayanan internal merupakan kriteria pelayanan yang paling berpengaruh dalam pelayanan kereta komuter Surabaya-Lamongan

2. Faktor yang paling berpengaruh dalam pelayanan kereta komuter Surabaya-Lamongan adalah faktor kehandalan, waktu, kenyamanan, biaya, dan aksesbilitas

3. Variabel yang paling penting dalam pelayanan kereta komuter adalah ketepatan kereta komuter, lama perjalanan kereta komuter, frekuensi pelayanan kereta komuter dan angkutan umum, kenyamana kereta komuter, tarif kereta komuter, inovasi pelayanan kereta komuter, ketersediaan informasi kereta komuter, serta keamanan kereta komuter dan angkutan umum. Variabel ini merupakan variabel yang termasuk prioritas peningkatan pelayanan kereta komuter.

4. Melalui analisis, kemudian dilakukan arahan peningkatan pelayanan terhadap variabel prioritas yang disesuaikan dengan peraturan yang ada, sehingga diharapkan bisa meningkatkan kualitas dan okupansi penumpang kereta komuter Surabaya-Lamongan.

\section{DAFTAR PUSTAKA}

[1] W. Dewantoro, D., \& Widodo, "Analisis Preferensi Masyarakat terhadap Penggunaan Jasa Pelayanan Transportasi Bus AKDP Semarang-Kendal (Studi Kasus: Komuter Semarang-Kendal)," 2015.

[2] M. Dwiriastya, C., \& Miharja, "Studi Preferensi Komuter Pengguna Moda Transportasi Pribadi Roda Empat terhadap Moda Transportasi Publik Terintegrasi (Studi Kasus: Koridor Kota Bekasi - DKI Jakarta )," J. Perencanan Wil. dan Kota A SAPPK, vol. 4, pp. 795-801, 2015.

[3] R. Pambudi, "Analisis Kinerja KA Komuter Surabaya Lamongan," Institut Teknologi Sepuluh Nopember, 2010.

[4] Pemerintah Provinsi Jawa Timur, Rencana Induk Perkeretaapian Provinsi Jawa Timur 2016-2036. Surabaya: Pemerintah Provinsi Jawa Timur, 2016.

[5] E. Bramianto, Preferensi Penggunaan Moda Angkutan Umum (Suatu Kajian di Wilayah Jakarta Pusat). Depok: Perpustakaan Universitas Indonesia, 2005.

[6] T. Saaty, Pengambilan Keputusan bagi Para Pemimpin, Alih Bahasa Ir. Liana Setiono. Jakarta: PT. Gramedia Pustaka Utama, 1993.

[7] L. L. Parasuraman, A., Zeithaml, V. A., \& Berry, "SERVQUAL: A Multiple-Item Scale for Measuring Consumers Perceptions of Service Quality," J. Retail., vol. 64, pp. 12-40, 1988.

[8] B. Bungin, Analisis Data Penelitian Kualitatif. Jakarta: PT. Rajagrafindo Persada, 2010. 